\title{
Wireless Internet Connection for Teaching and learning in Rural Schools of South Africa: The University of Limpopo TV White Space Trial Project
}

\author{
Ms Tlou Ramoroka \\ Lecturer, Department of Development Planning and Management, University of Limpopo \\ Email: Millicent.Ramoroka@ul.ac.za
}

\author{
Doi:10.5901/mjss.2014.v5n15p381
}

\begin{abstract}
There is a need for technological advancement in teaching and learning especially in mixed development economies such as South Africa. Lately, the vacant channels within the television spectrum known as white spaces are used to deliver wireless internet connection through the geo-location databases. This connection of internet through the TV white spaces is believed to have positive effects on teaching and learning especially for the previously disadvantaged schools mostly located in rural areas and townships. The benefits of using Information and Communication Technologies (ICT) for teaching and learning includes improved interaction amongst students and teachers; development of critical thinking; data collection and analysis skills and improved class participation, among others. However, there are also challenges which are associated with teaching and learning using ICT which include, among others, lack of teacher training to use ICT; requirements of the national curricula and lack of infrastructure. This paper outlines the benefits and challenges of using TV white spaces for internet connection in rural and township schools. The University of Limpopo TV White Spaces trial project is used as a case study to illustrate the benefits and challenges thereof. The paper then concludes that the use of ICT have the ability to positively improve teaching and learning in South Africa's rural and township schools.
\end{abstract}

Keywords: Wireless Internet, Teaching, Learning, TV White Space, University of Limpopo

\section{Introduction and Background}

Lately, the dynamic spectrum sharing which is enabled by geo-location databases has been used to increase the availability and accessibility of wireless internet connection (Ahmadi, Keshavarzi \& Foroutan, 2011; Makgato, 2012; Carlson, Ntlatlapa, King, Mgwili-Sibanda, Hart and Geerdts, 2013; Han, Eom \& Shin, 2013; Lin, Zhang, Jung \& Kim, 2013; Lysko, Masonta \& Mfupe, 2013; Mwangoka, Marques \& Rodriguez, 2013; Rolando, Salvador \& Luz, 2013). The need to increase the spectrum sharing is a result of the increasing numbers of new entrants in the wireless services markets which include machine-to-machine communications, internet access, amongst others, and the capacity improvements of current operators (Ahmadi et al., 2011; Mwangoka et al., 2013; Tagger, Trossen, Kostopoulos, Porter \& Parisis 2013). Thus, the vacant channels which are called white spaces within the television spectrum are used to deliver wireless internet connection through the geo-location databases as a response to the increasing need for technological innovation.

According to Carlson et al. (2013: 8), TV White spaces are "portions of radio spectrum that are allocated for licenced use but are not assigned to a particular licensee or are allocated and assigned for licensed use but are not utilised by the licensees at all times or across all geographic locations". In addition, Lysko et al. (2013: 6) define TV White Spaces as "unused spectrum in the TV spectrum bands at a specific geographical location that can be used for alternative wireless communication services". Through spectrum sensing, the geo-locational databases used are able to detect the available channels which can be used for wireless internet connection especially for the previously disadvantaged rural areas and townships in order to bridge the digital gap that exists between the rich and poor. Furthermore, the TV White Spaces can provide wireless internet connection at low-costs without interfering with the TV reception.

Internationally, with the exception of the United States of America (USA) and United Kingdom (UK), the opportunity of the usage of TV White Spaces for internet connection has not been fully taken advantage of (Ahmadi et al., 2011; Han et al., 2013; Mwangoka et al., 2013; Fuentes-Bautista, 2014). The limited usage of the white spaces is due to uncertainties in enabling and supporting technologies, potential business models and regulatory policies (Carlson et al., 2013; Mwangoka et al., 2013). However, research indicates that countries such as Kenya, Tanzania, Malawi, Finland, The Philippines, and Singapore are amongst the few which use white spaces for wireless internet connection (Han et al., 
2013; Carlson et al., 2013;). In South Africa, there are two TV White Space trial projects which are in progress. The first trial project was launched in the Western Cape Province in Cape Town on March 25, 2013. The launched trial project provides internet access to ten schools within a $10 \mathrm{~km}$ radius of the Stellenbosch University. The second trial project was launched in Limpopo Province in Mankweng Township near Polokwane City on June 18, 2014. The project provides wireless internet connection to five rural and township schools located within $8 \mathrm{~km}$ radius of the University of Limpopo which serves as the centre for the TV White Space Base. It is in this context that this paper consists of four sections including this introduction. The second section discusses the benefits and challenges of using Information and Communication Technologies (ICT) for teaching and learning. In the third section the use of TV White Spaces for internet connection for the selected rural and township schools around the University of Limpopo, Turfloop Campus is discussed. Then the last section concludes this paper.

\section{Information and Communication Technologies for Teaching and Learning: Benefits and Challenges}

Currently, successful teaching and learning is driven by technology and its related softwares, infrastructure and services (Ahmadi et al., 2011; Makgato, 2012; Marinagi, Skourlas \& Belsis, 2013; Rolando et al., 2013; Tagger et al., 2013; Yang, 2013; Yoon, Lee, \& Lee, 2013). The use of internet, telecommunications, wireless applications, handheld electronics, social network softwares and the web, amongst others, explains how people acquire information, teach and learn (Ahmadi et al., 2011; Yang, 2013; Rolando et al., 2013; Fuentes-Bautista, 2014). Thus, the increasing use of these devices, engines and softwares deemed it necessary to rely on electronic media, assisted instruction information and communication technologies for teaching and learning popularly known as e-learning. This e-learning include multimedia learning, technology-enhanced learning, computer-based instruction, computer-based training, computer-assisted instruction, internet-based training and web-based training, amongst others (Ahmadi et al., 2011; Makgato, 2012; Yang, 2013; Yoon et al., 2013). Furthermore, e-learning includes different types of media that are meant to deliver text, audio, images, and videos that enhance teaching and learning (Ahmadi et al., 2011; Rolando et al., 2013; Tagger et al., 2013). Despite the importance associated with teaching and learning using ICT, there are a number of benefits and challenges encountered which are discussed respectively in the proceeding subsections:

\subsection{Benefits of ICT for Teaching and Learning}

Some of the international institutions such as the British Educational Communications and Technology Agency (BECTA, 2003), the World Bank (2008) and the United Nations Educational, Scientific and Cultural Organization (UNESCO, 2008) have been promoting the use of ICT for teaching and learning purposes. Accordingly, the Asian, European and British countries have adopted public policies which are meant to increase the use of ICT for teaching and learning (Rolando et al., 2013). The adopted policies include the provision of high speed access to internet, hardware and other digital resources, technical support to the needy schools and professional developments for teachers (Marinagi et al., 2013; Rolando et al., 2013).

Through the use of ICT, learners and teachers can interact amongst each other and even learn from each other (Lin et al., 2013; Yang, 2013; Yoon et al., 2013; Fuentes-Bautista, 2014). International research revealed that about 60\% of students use social networking tools to discuss class related issues which encourages learning outside schools and planning for the next lessons (Ahmadi et al., 2011; Marinagi et al., 2013; Rolando et al., 2013; Yang, 2013). Seemingly, apart from communicating with parents and friends, learners use social networks as a platform to discuss school work. In addition, ICT can be used to encourage and support real life related problems for learning and teaching both in and outside the classrooms (Makgato, 2012; Han et al., 2013; Lin et al., 2013; Marinagi et al., 2013; Rolando et al., 2013; Tagger et al., 2013; Fuentes-Bautista, 2014). According to Han et al. (2013), the uses of ICT in the classrooms capture real life situations better than print-base materials which usually present events in a linear format. Thus, the incorporation of ICT gives learners a feel of what is going on outside their classrooms while preparing them to be able to solve real and complex problems.

ICT assist students and teachers in developing critical thinking, data collection and analysis skills and further promote active class participation (Makgato, 2012; Han et al., 2013; Lin et al., 2013; Marinagi et al., 2013; Yoon et al., 2013; Fuentes-Bautista, 2014). The skills will assist both teachers and learners in solving challenges and problems that they face in their everyday lives. Accordingly, access to knowledge through ICT which is mostly presented in a visual format will be used to improve learning and teaching. South Africa's Department of Education (RSA, 2003) asserted that the use of ICT for teaching and learning contributes to the developments of literacy and skills to deal with technological problems both amongst teachers and learners. Generally, ICT in teaching and learning can improve the knowledge and 
skills of both teachers and learners, develop better educational structure of high quality and encourage comprehensive learning (Ahmadi et al., 2011; Han et al., 2013; Lin et al., 2013; Marinagi et al., 2013; Yoon et al., 2013). Therefore, the use of TV White Spaces for wireless internet connection, especially in rural areas and townships will support and further encourage the use of other related ICT tools for effective and efficient teaching and learning.

\subsection{Challenges Associated with Teaching and Learning Using ICT}

Despite a number of benefits associated with the use of ICT for teaching and learning, there are challenges which are being faced by teachers as well as learners in education. In most cases, teachers lack content knowledge necessary to be able to use ICT in their teaching as a result of limited/lack of training (Makgato, 2012; Han et al., 2013; Lin et al., 2013; Marinagi et al., 2013; Rolando et al., 2013; Fuentes-Bautista, 2014). Therefore, the same teachers are being blamed for their inability to teach learners with the content knowledge and skills of ICT (Makgato, 2012; Marinagi et al., 2013). The use of ICT will be effective and efficient only if teachers are well trained to incorporate it in their teaching. Research revealed that regardless of the use of ICT for teaching and learning, most teachers rarely use it in ways that are beneficial to educational contexts (Han et al., 2013; Marinagi et al., 2013; Rolando et al., 2013; Yoon et al., 2013). In most cases, the use of ICT by teachers is common for class and test preparations, personal communication through e-mails and other social networks and not for teaching to enhance effective and efficient learning.

The limited use of ICT for teaching and learning in most schools is however, influenced by a number of factors which include restricted teachers' knowledge and abilities to use ICT, the demanding national curricula and lack of infrastructure, amongst others (Rolando et al., 2013; Yoon et al., 2013). Moreover, some learners do not know how to use ICT related softwares and infrastructures effectively for their own learning which makes it difficult for them to realise the benefits associated with ICT for learning purposes (Ahmadi et al., 2011; Lin et al., 2013; Marinagi et al., 2013; Tagger et al., 2013; Yoon et al., 2013). In some cases, there are limited infrastructure and equipments to promote, encourage and support the use of ICT for teaching and learning in most schools especially many of those which are located in townships and rural areas (Makgato, 2012; Han et al., 2013; Rolando et al., 2013). For most rural and township schools, the available computers are only accessible to teachers who mostly use them for personal communication rather than for teaching purposes. As a result, the learners from such schools find it very hard to adapt to the use of ICT when they get to the higher institutions of learning. Apart from the required training to use ICT for teaching and learning, most rural and township schools do not afford the infrastructure and the softwares needed.

\section{TV White Spaces for Wireless Internet Connection in Rural Areas and Townships Around the University of Limpopo: The Second Trial Project in South Africa}

The University of Limpopo emerged in 2005 as a result of the merger of the then University of the North and the Medical University of South Africa (MEDUNSA) located in Mankweng (Limpopo Province) and Ga-Rankuwa Townships (Gauteng Province), respectively. Both campuses were established to serve the educational needs of the majority of the Black population during the apartheid era. However, the TV White Space Trial Project is hosted by the campus in Mankweng Township popularly known as the Turfloop Campus. The campus is located about $40 \mathrm{~km}$ East of Polokwane City and half-way between the city and Magoebaskloof. The University of Limpopo, Turfloop Campus in collaboration with the CSIR, Microsoft and Multisource host a project aimed at providing wireless internet connection to rural areas and townships within $10 \mathrm{~km}$ radius of the university. The key mentioned partners of the initiated project play different roles in ensuring that the project becomes a success. For example, the University of Limpopo acts as an enabler by driving the trial network in order to provide the five selected schools with wireless internet connection. The CSIR co-funds the project and provide backup database needed for the project. The institution further acts as the collaborator on White Space Databases communication protocol. Microsoft which is the co-funder of the project provides e-services developer and primary database, tablets and softwares to the selected 5 schools and also acts as the collaborator on White Space Databases communication protocol. Furthermore, Microsoft offers ICT training to the selected teachers and learners of the schools which are the beneficiaries of the project.

Microsoft in collaboration with Multisourse provide solar-powered stations in order to be able to provide high speed internet access to areas which lack electricity. The connection of the wireless internet through the TV White Spaces from the University of Limpopo requires the Geo-location database that the CSIR has developed for Limpopo Province. Additionally, the CSIR test spectrum licence on Ultra High Frequencies (UHF) from Independent Communications Authority of South Africa (ICASA) for TV White Spaces networks which will be used to facilitate the network for this trial project. The University of Limpopo is currently connected to the South African National research Network (SANReN) 
through an optic fiber and microwave link. The SANReN was developed by the CSIR in order to create a new national research and education network in South Africa. Thus, the University of Limpopo's SANReN link provides the backhaul to the TV White Spaces trial network and access to the wireless internet. The TV White Space Base will be located in the Turfloop Campus and each school hosts a White Space Device which will be connected to the base. Although the initial distance between the TV White Space Base and the White Space Device was $10 \mathrm{~km}$, schools located more than the distance may have a chance of being connected in future depending on the link quality and the installed microwave links.

The objective of this trial project is to provide and improve the limited technology access in rural areas and townships by delivering low-cost and high-speed wireless internet connection. The connection to the internet network through the University of Limpopo is expected to improve and create new opportunities for commerce, education, healthcare and the delivery of other government services in the identified areas. However, for the purpose of this trial project, only selected schools are connected to the wireless internet. The University of Limpopo's School of Education and the Department of Computer Science identified five areas which include Tshware (Ga-Maredi), Mamotintane, Badimong Village, Ga-Mothiba (Nobody) and Mankweng Township which house Doasho, Mamabudusha, Mphetsebe, Ngwanalaka and Mountainview High Schools, respectively. The selected schools provide a mixture between quintile 1 (poorest) and quintile 4 (least poor) in order to have a variety of schools benefiting from the project.

In addition to the benefits discussed in the previous section of this paper, the trial wireless internet connection will assist in improving the University of Limpopo teachers' training. The University's School of Education has a programme were post-graduate students (teachers) visit local schools for their practical training and other related projects. Therefore, with access to wireless internet connection, the university students will be able to effectively and efficiently use the internet contents for their practical training. These students can also assist the full-time school teachers on how to use the internet contents for teaching and learning and not just for their personal communication. Additionally, the wireless internet connection can be used to develop, test and implement educational applications which are necessary to improve teaching and learning in these schools. The internet connection can also be used for computer literacy self-study certification lessons for pupils and teachers within the identified schools. However, this benefit can only be realised by those schools which have computer laboratories. The lessons will be offered by the University of Limpopo's Department of Computer Science in collaboration with its post-graduate students. In future, other possible benefits of the wireless internet connection might include the provision of the TV White Space enabled digital doorway, connectivity of the rural clinics for improved healthcare service and connecting the university's Syferkuil Agricultural Centre in order to improve the services it renders to the community.

\section{Conclusion}

This paper demonstrated how the use of TV White Spaces for wireless internet connection and ICT can assist in improving teaching and learning. The TV White Spaces can be used effectively and efficiently to connect previously disadvantaged townships and rural areas to wireless internet which can be used to develop teaching and learning within these areas. However, the best results associated with the use of ICT for teaching and learning do not come without challenges. The challenges of using ICT for teaching and learning discussed in this paper include lack of teachers' and learners' knowledge and skills, limited infrastructure and the use of internet connection for personal communications. In addressing the identified challenges, the University of Limpopo, Turfloop Campus in collaboration with the CSIR, Microsoft and Mltisource provides wireless internet connection to five selected rural schools within $8 \mathrm{~km}$ radius of the university. Limited or lack of infrastructure such as laboratories and computers and human resources necessary to promote the use of ICT within the five selected schools is also taken into consideration. Depending on the needs of the learners and teachers, some of the partners provided the needed infrastructure and the equipments as identified per school in order to ensure that the trial project becomes a success.

\section{References}

Ahmadi, S., Keshavarzi, A. \& Foroutan, M. (2011) The application of Information and Communication Technologies and its relationship with improvement in teaching and learning. Procedia-Social and Behavioural Sciences 28: 475-480.

Carlson, J., Ntlatlapa, N., King, J., Mgwili-Sibanda, F., Hart, A. \& Geerdts, C. (2013) Studies

on the Use of Television White Spaces in South Africa: Recommendations and Learnings from the Cape Town Television White SpacesTrial. https://www.tenet.ac.za/tvws/recommendation-and-learnings-from-the-cape-town-tv-white-spaces-trial. Accessed December 05, 2013.

Clarke, R.N. (2013) Expanding mobile wireless capacity: the challenges presented by technology and economics. Telecommunications Policy. http://dx.doi.org/10.1016/j.telpol.2013.11.006. Accessed April 14, 2014. 
Fuentes-Bautista, M. (2014) Rethinking localism in the broadband era: a participatory community development approach. Government Information Quarterly 31: 65-77.

Han, I., Eom, M. \& Shin, W.S. (2013) Multimedia case-based learning to enhance pre-service teachers' knowledge integration for teaching with technologies. Teaching and Teacher Education 34: 122-129.

Lin, W., Zhang, X., Jung. J. \& Kim, Y. (2013) From the wired to wireless generation? Investigating teens' internet use through the mobile phone. Telecommunications Policy 37: 651-661.

Lysko, A., Masonta, M., \& Mfupe, L. (2013) Field Measurements Done on Operational TVWS Trial Network in Tygerberg. Council for Scientific and Industrial Research, Pretoria.

Makgato, M. (2012) Identifying constructive methodologies and pedagogic content knowledge in teaching and learning of technology. Procedia-Social and Behavioural Sciences 47: 1398-1402.

Marinagi, C., Skourlas, C. \& Belsis, P. (2013) Employing ubiquitous computing devices and technologies in the higher education classroom of the future. Procedia-Social and Behavioural Sciences 73: 487-494.

Mwangoka, J.W., Marques, P. \& Rodriguez, J. (2013) TV white spaces exploitation through a bicameral geo-location database. Telecommunications Policy 37: 116-129.

Republic of South Africa (RSA) (2003) Revised national curriculum statement Grades R-9:

teacher's guide for the development of learning programmes' technology. Government Printers, Pretoria.

Rolando, L.G.R., Salvador, D.F. \& Luz, M.R.M. (2013) The use of internet tools for teaching and learning by the in-service biology teachers: a survey in Brazil. Teaching and Teacher Education 34: 46-55.

Tagger, B., Trossen, D., Kostopoulos, A., Porter, S. \& Parisis, G. (2013) Realising an application environment for information-centric networking. Computer Networks 57: 3249-3266.

Yang, H.H. (2013) New world, new learning: trends and issues of e-learning. Procedia- Social and Behavioural Sciences 77: 429-442.

Yoon, S.Y., Lee, J. \& Lee, C.H. (2013) Interacting with screenagers in classrooms. Procedia: Social and Behavioral Sciences 103: 534541. 